\title{
Amiloride-sensitive cation channel 2 genotype affects the response to a carbon dioxide panic challenge
}

Citation for published version (APA):

Leibold, N. K., van den Hove, D. L. A., Viechtbauer, W., Kenis, G., Goossens, L., Lange, I., Knuts, I., Smeets, H. J., Myin-Germeys, I., Steinbusch, H. W. M., \& Schruers, K. R. J. (2017). Amiloride-sensitive cation channel 2 genotype affects the response to a carbon dioxide panic challenge. Journal of

Psychopharmacology, 31(10), 1294-1301. https://doi.org/10.1177/0269881116686880

Document status and date:

Published: 01/10/2017

DOI:

10.1177/0269881116686880

Document Version:

Publisher's PDF, also known as Version of record

Document license:

Taverne

Please check the document version of this publication:

- A submitted manuscript is the version of the article upon submission and before peer-review. There can be important differences between the submitted version and the official published version of record.

People interested in the research are advised to contact the author for the final version of the publication, or visit the DOI to the publisher's website.

- The final author version and the galley proof are versions of the publication after peer review.

- The final published version features the final layout of the paper including the volume, issue and page numbers.

Link to publication

\footnotetext{
General rights rights.

- You may freely distribute the URL identifying the publication in the public portal. please follow below link for the End User Agreement:

www.umlib.nl/taverne-license

Take down policy

If you believe that this document breaches copyright please contact us at:

repository@maastrichtuniversity.nl

providing details and we will investigate your claim.
}

Copyright and moral rights for the publications made accessible in the public portal are retained by the authors and/or other copyright owners and it is a condition of accessing publications that users recognise and abide by the legal requirements associated with these

- Users may download and print one copy of any publication from the public portal for the purpose of private study or research.

- You may not further distribute the material or use it for any profit-making activity or commercial gain

If the publication is distributed under the terms of Article $25 \mathrm{fa}$ of the Dutch Copyright Act, indicated by the "Taverne" license above, 


\section{Amiloride-sensitive cation channel 2 genotype affects the response to a carbon dioxide panic challenge}

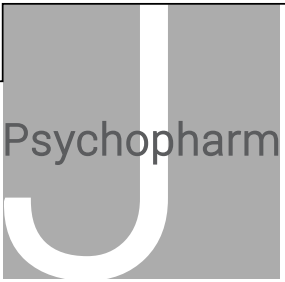

Journal of Psychopharmacology 2017, Vol. 31(10) 1294-1301 (c) The Author(s) 2017 Reprints and permissions: sagepub.co.uk/journalsPermissions.nav DOI: $10.1177 / 0269881116686880$ journals.sagepub.com/home/jop

\author{
Nicole K Leibold ${ }^{1}$, Daniel LA van den Hove ${ }^{1,2}$, Wolfgang Viechtbauer ${ }^{1}$, \\ Gunter Kenis ${ }^{1}$, Liesbet Goossens ${ }^{1}$, Iris Lange ${ }^{1}$, Inge Knuts ${ }^{1}$, \\ Hubert J Smeets ${ }^{3}$, Inez Myin-Germeys ${ }^{1}$, Harry WM Steinbusch ${ }^{1}$ \\ and Koen RJ Schruers ${ }^{1}$
}

(S)SAGE

\begin{abstract}
Until recently, genetic research into panic disorder (PD) has had only limited success. Inspired by rodent research, demonstrating that the acid-sensing ion channel 1a (ASIC1a) is critically involved in the behavioral fear response to carbon dioxide $\left(\mathrm{CO}_{2}\right)$ exposure, variants in the human homologue gene amiloride-sensitive cation channel 2 ( $A C C N 2$ ) were shown to be associated with PD. However, the relationship between changes in brain $\mathrm{pH}$ and ACCN2, as done in rodents by $\mathrm{CO}_{2}$ exposure, has not been investigated yet in humans. Here, we examined this link between the ACCN2 gene and the response to $\mathrm{CO}_{2}$ exposure in two studies: in healthy volunteers as well as PD patients and using both behavioral and physiological outcome measures. More specifically, 107 healthy volunteers and 183 PD patients underwent a $35 \% \mathrm{CO}_{2}$ inhalation. Negative affect was assessed using visual analogue scales and the panic symptom list (PSL), and, in healthy volunteers, cardiovascular measurements. The single nucleotide polymorphism rs 10875995 was significantly associated with a higher emotional response in PD patients and with an increase in systolic as well as diastolic blood pressure in healthy subjects. In all measurements, subjects homozygous for the T-allele showed a heightened reactivity to $\mathrm{CO}_{2}$. Furthermore, a trend towards an rs685012 genotype effect on the emotional response was found in PD patients. We provide the first evidence that genetic variants in the ACCN2 are associated with differential sensitivity to $\mathrm{CO}_{2}$ in PD patients as well as healthy volunteers, further supporting ACCN2 as a promising candidate for future research to improve current treatment options.
\end{abstract}

Keywords

Panic disorder, carbon dioxide exposure, ACCN2, ASIC1a, fear

\section{Introduction}

Panic disorder (PD) is a highly prevalent and debilitating condition characterized by recurrent, unexpected panic attacks (PAs) (American Psychiatric Association, 2013). Based on clinical and epidemiological data, a division in subtypes is made, with predominant respiratory or cardiovascular symptoms compromising a "core panic type" (Roberson-Nay and Kendler, 2011). PD is associated with high healthcare costs (Batelaan et al., 2007) and in spite of available treatments, long-term effects are modest and relapse rates are high (Yonkers et al., 2003). Insight into the molecular and genetic mechanisms of the disorder would arguably be beneficial in the search for improved and new treatments.

Until recently, genetic research into PD has been relatively scarce and less successful compared to other psychiatric disorders (Smoller, 2011). Inspired by previous work in mice, attention has been turned to the amiloride-sensitive cation channel 2 (ACCN2), the human homologue to the rodent acid-sensing ion channel 1a (ASIC1a). ASIC1a was shown to play an important role in conditioned fear (Wemmie et al., 2003, 2004), but the interest in ASIC1a in relation to PD was boosted by a seminal study (Ziemann et al., 2009) showing that ASIC1a is also essentially involved in the unconditioned behavioral fear response to carbon dioxide $\left(\mathrm{CO}_{2}\right)$ exposure by acting as a chemosensor that detects a decrease in extracellular $\mathrm{pH}$.
Analogs can be drawn to humans, in whom $\mathrm{CO}_{2}$ exposure has proven to be a reliable experimental model for panic. PD patients display a higher fear and panic response to $\mathrm{CO}_{2}$ when compared to healthy volunteers (Griez et al., 1987, 1990). A brief inhalation of $35 \% \mathrm{CO}_{2}$ triggers short lasting, but intense symptoms resembling the ones of a naturally occurring PA in PD patients (Nardi et al., 2006; Schruers et al., 2004). We proposed that an acutely disturbed acid-base homeostasis represents the mechanism underlying the occurrence of PAs (Esquivel et al., 2009), thereby forming the molecular basis of the suffocation false alarm theory

${ }^{1}$ Department of Psychiatry and Neuropsychology, Maastricht University, Maastricht, the Netherlands

2Department of Psychiatry, Psychosomatics and Psychotherapy, University of Würzburg, Würzburg, Germany

${ }^{3}$ Genome Center Maastricht, Maastricht University, Maastricht, the Netherlands

\section{Corresponding author:}

Nicole Leibold, Department of Psychiatry and Psychology, Maastricht University, P.0. Box 616 (Vijverdal), 6200 MD Maastricht, the Netherlands.

Email: nicole.leibold@maastrichtuniversity.nl 
(Klein, 1993; Preter and Klein, 2008). $\mathrm{CO}_{2}$ exposure was shown to cause a decrease in brain $\mathrm{pH}$ in rodents (Schuchmann et al., 2006; Ziemann et al., 2008, 2009). While studies investigating the direct effects of breathing $\mathrm{CO}_{2}$ on brain $\mathrm{pH}$ in humans are lacking, indirect evidence for brain acidification comes from a study using intravenous infusion of bicarbonate, which caused a decrease in brain $\mathrm{pH}$ as shown by magnetic resonance spectroscopy (Nakashima et al., 1996). The acid-base homeostasis is tightly regulated within a narrow range and a shift out of the normal range can have fatal consequences (Rhoades and Bell, 2009). Therefore, sensing a change in $\mathrm{pH}$ and triggering adaptive physiological and behavioral responses are of crucial importance for an individual's survival. Hence, genes encoding for molecules involved in chemosensation such as $A C C N 2$ present a pivotal link between $\mathrm{pH}$ and panic.

To date, only a few studies investigated the link between $A C C N 2$ and PD. In a first study (Hettema et al., 2008), the C-allele of the single nucleotide polymorphisms rs685012, located in the $5^{\prime}$ putative promoter region, was associated with anxiety disorder. The replication of this association failed, however, in a second larger sample. This is probably due to assessing a group of mixed anxiety disorder patients of whom only a subset had PD. In a large case-control study, Smoller and colleagues (2014) demonstrated that the C-allele of rs685012 and of rs10875995, located in intron 3, was associated with increased probability of having the diagnosis of PD. Similarly, a significant increase in the frequency of the rs685012 C-allele in PD patients was recently reported by Gugliandolo et al. (2016). In healthy volunteers, Smoller et al. (2014) observed that the C-allele was associated with a larger amygdala volume and heightened amygdala reactivity to visual presentation of fearful and angry faces.

The proposed mechanism linking $A C C N 2$ and panic in humans involves an altered threshold for sensing acidosis (Smoller et al., 2014). More specifically, variants in the $A C C N 2$ gene may lead to a lower threshold for detecting a decrease in $\mathrm{pH}$, resulting in a heightened sensitivity to cues from within the body (caused by, e.g. $\mathrm{CO}_{2}$ exposure). This mechanism is highly plausible, but experimental evidence linking differential $\mathrm{CO}_{2}$ reactivity in humans to variants in the $A C C N 2$ gene is currently lacking. For many years it was assumed that, in contrast to PD patients, healthy volunteers are not sensitive to breathing $\mathrm{CO}_{2}$ (Griez et al., 1987). However, by now, a dose-response relationship between $\mathrm{CO}_{2}$ and reported fear and bodily symptoms has been repetitively shown (Griez et al., 2007; Schruers et al., 2011), whereby a double inhalation of $35 \% \mathrm{CO}_{2}$ elicits a response that closely resembles the one reported by PD patients to a single vital capacity inhalation. These observations imply the existence of a $\mathrm{CO}_{2}$-reactivity continuum and that panic symptoms can be provoked in most individuals, depending on the concentration of $\mathrm{CO}_{2}$ used. The findings suggest that $\mathrm{CO}_{2}$ inhalation activates basic fear mechanisms that are present in every individual. This opens the avenue of studying panic-related fear in healthy volunteers, thus bridging the gap between animal models and research in PD patients.

The present study sought to investigate the relationship between the response to $\mathrm{CO}_{2}$ and the $A C C N 2$ gene, with a focus on the two gene variants previously found to be associated with $\mathrm{PD}$ and amygdala reactivity. In the first study, we assessed the response to $\mathrm{CO}_{2}$ in healthy individuals. To capture the emotional and the physiological reactivity, we examined the effects of $\mathrm{CO}_{2}$ on self-reported emotions as well as the cardiovascular system.
In the second study, in light of clinical relevance, the self-reported emotional response to $\mathrm{CO}_{2}$ was evaluated in $\mathrm{PD}$ patients.

\section{Experimental procedures}

\section{Study 1: healthy individuals}

Subjects. One-hundred and seven Caucasian adult healthy volunteers participated in this study (mean age 23.76 years, $\mathrm{SD}=6.96 ; 27$ males; part of a previous sample (Leibold et al., 2013)). Subjects were recruited via advertisements at Maastricht University, the Netherlands. Eligibility was confirmed using a standard medical examination and a semi-structured psychiatric interview including the Mini International Neuropsychiatric Interview (MINI, Sheehan et al., 1998), performed by an experienced psychiatrist or psychologist. Exclusion criteria included current or past cardiovascular or pulmonary disease, hypertension (systolic/diastolic $>170 / 100$ $\mathrm{mmHg}$ ), familial or personal history of cerebral aneurysm, smoking ( $>15$ cigarettes per day), pregnancy, epilepsy, use of psychotropic medication or adrenergic receptor blockers, and a first-degree relative with PD. All participants gave written informed consent prior to the study. The study was approved by the Medical Ethics Committee of Maastricht University and the Maastricht University Hospital.

$\mathrm{CO}_{2}$ inhalation. The standardized protocol for $\mathrm{CO}_{2}$ inhalations in healthy volunteers has been described previously (Griez et al., 2007). In brief, subjects were informed that $\mathrm{CO}_{2}$ might cause some effects, ranging from minor sensations up to fear. However, all effects would be short-lasting. Subjects took a double vital capacity breath of $35 \% \mathrm{CO}_{2}$. All subjects inhaled at least $80 \%$ of their vital capacity as measured using a flowmeter. Subjects were instructed to refrain from caffeine containing beverages on all inhalation days.

Self-reports. The affective response to $\mathrm{CO}_{2}$ was evaluated in accordance with the DSM-IV criteria for a PA (American Psychiatric Association, 2000). Fear and discomfort were assessed using the Visual Analogue Scale (VAS-F and VAS-D, respectively), consisting of a horizontal line of $100 \mathrm{~mm}$ length and ranging from 0 (not at all) to 100 (the worst imaginable). Panic symptomatology was evaluated using the panic symptom list (PSL), a questionnaire listing the 13 DSM PA symptoms such as palpitations, sweating, shortness of breath, dizziness, and choking, and ranging from 0 (absent) to 4 (very intense). Self-reports were obtained directly before and immediately after the inhalation.

Cardiovascular recordings. Blood pressure and heart rate were measured continuously throughout the entire procedure in healthy volunteers using a computerized system (Carbon Dioxide Tolerance Tester, CTT, Maastricht Instruments BV, Maastricht, the Netherlands). Both parameters were measured by means of a finger cuff that was connected to a cardiovascular monitor (Nexfin, BMEYE BV, Amsterdam, the Netherlands). All measurements were acquired with custom-made software (IDEEQ, Maastricht Instruments BV, Maastricht, the Netherlands).

\section{Study 2: PD patients}

Subjects. One-hundred and eighty-three Caucasian PD patients (mean age 36.14 years, $\mathrm{SD}=10.94 ; 71 \mathrm{men}$ ) participated in this 
study. Patients were recruited from the outpatient setting of the Academic Anxiety Centre, Maastricht, the Netherlands. PD (with or without agoraphobia) as main diagnosis was established via a semi-structured psychiatric interview by an experienced psychiatrist, including the MINI (Sheehan et al., 1998) (see assessment scores shown in Supplementary table 1 online). Patients underwent a standard medical examination to confirm eligibility. Exclusion criteria were current or past cardiovascular or pulmonary disease, hypertension (systolic/diastolic $>170 / 100 \mathrm{mmHg}$ ), familial or personal history of cerebral aneurysm, pregnancy, and epilepsy. In total, 106 patients had one or more comorbid disorders. Patients were free of antidepressant and benzodiazepine treatment for at least 4 or 2 weeks, respectively, before taking part in the experiment. Written informed consent was obtained from each subject before participating. The study was approved by the Medical Ethics Committee of Maastricht University and the Maastricht University Hospital.

$\mathrm{CO}_{2}$ inhalation. In PD patients, $\mathrm{CO}_{2}$ inhalations took place according to a standardized protocol as described previously (Klaassen et al., 1998). Subjects were informed that the subsequent inhalation might cause some effects, ranging from minor sensations up to fear. However, all effects would be short-lasting. Subjects took a single vital capacity breath of $35 \% \mathrm{CO}_{2}$. Using a flowmeter it was ensured that at least $80 \%$ of their previously measured vital capacity was inhaled.

Self-reports. In line with the DSM-IV criteria for a PA (American Psychiatric Association, 2000), experienced fear was evaluated using the Visual Analogue Scale for fear (VAS-F), consisting of a horizontal line of $100 \mathrm{~mm}$ length and ranging from 0 (not at all) to 100 (the worst imaginable). Panic symptoms were assessed by means of the PSL, a questionnaire listing the 13 DSM PA symptoms, and ranging from 0 (absent) to 4 (very intense). Self-reports were obtained directly before and immediately after the inhalation.

\section{Genotyping}

Saliva was collected from all subjects using Oragene ${ }^{\circledR}$ saliva self-collecting kits (DNA Genotek Inc, Ontario, Canada). Genomic DNA was isolated using the AutoGenFlex DNA Isolation system (Autgen, Hilliston, MA, USA) according to manufacturer's instructions and subsequently genotyped using Taqman SNP Genotyping Assays for rs10875995 and rs685012 (Life Technologies). The selection of these particular polymorphisms was based on the results of the recent study by Smoller et al. (2014), in which an association with PD and amygdala reactivity was found. Results were independently scored by two experienced technicians.

\section{Data and statistical analysis}

Primary analyses. Differences in the change of self-reported emotions and symptoms depending on the genotype were analyzed using univariate analysis of variance (ANOVA). Six PD patients were excluded from the rs685012 analysis due to genotyping failure (final sample mean age 36.14 years, $\mathrm{SD}=$ 10.94; 71 men).
To analyze physiological measurements in healthy subjects, locally weighted polynomial regression (Cleveland and Devlin, 1988) was used to avoid strong effects of outliers. Based on smoothed data, the maximum, the area under the curve (AUC), and the standard deviation (log transformed) were calculated within the first $60 \mathrm{~s}$ after inhaling $\mathrm{CO}_{2}$. The maximum represents the highest value/peak in this period, which might reflect a few seconds of the response only. To capture the response in more detail, the AUC was calculated. The standard deviation serves as index for fluctuations caused by $\mathrm{CO}_{2}$. Due to a technical failure, the final sample for physiological analyses consisted of 92 subjects (mean age 23.56 years, $\mathrm{SD}=0.44 ; 24 \mathrm{men}$ ).

Secondary analysis. Patients with predominantly respiratory symptoms during their PAs have been proposed as forming a "core" panic subtype (Roberson-Nay and Kendler, 2011). Smoller et al. (2014) showed a particularly strong relationship between $A C C N 2$ genotype and such a respiratory panic subtype. We have previously demonstrated the existence of a similar respiratory subtype in response to a $\mathrm{CO}_{2}$ challenge (Colasanti et al., 2008). Analysis of the respiratory cluster was based on this previous cluster analysis study (Colasanti et al., 2008) and consisted of the symptoms shortness of breath, feeling of choking, dizziness, sweating, palpitations, and chest pain. The effect of genotype on the sum of the change scores of these six symptoms was analyzed by means of univariate ANOVA.

Based on Smoller et al. (2014), C-allele carriers were compared to $\mathrm{T} / \mathrm{T}$ homozygotes in all analyses for both polymorphisms. Significance was set at $p<0.05$. All analyses were performed using the Statistical Package for the Social Sciences (SPSS 20.0.0.1 for Mac; SPSS Inc., Chicago, IL) or the software R (version 3.1.1, 2014, R Development Core Team, Vienna/Austria).

\section{Results}

Demographical data of healthy volunteers and PD patients are presented in Table 1. The distribution of $A C C N 2$ genotypes was in Hardy-Weinberg equilibrium for both samples. Genotypes did not differ with respect to sex and age and the duration of PD.

\section{Study 1: Healthy volunteers}

Self-reports to $\mathrm{CO}_{2}$ inhalation. In healthy volunteers, no effect of the rs10875995 genotype on the change score regarding VAS-F ( $p=0.264$, Figure 1(a)), VAS-D $(p=0.208)$, and PSL ( $p$ $=0.196$, means shown in Supplementary table 2 ) was present. No rs685012 genotype effect was found on VAS-F ( $p=0.646$, Figure $2(\mathrm{a}))$, VAS-D $(p=0.131)$, and PSL ratings $(p=0.453$, means shown in Supplementary table 3 ).

Cardiovascular response to $\mathrm{CO}_{2}$ inhalation. Healthy subjects homozygous for the T-allele of rs10875995 showed a significantly higher AUC ( $p=0.043$, means shown in Supplementary table 4$)$ and a tendency towards a higher peak $(p=0.089)$ of the systolic blood pressure after the $\mathrm{CO}_{2}$ inhalation. Similarly, also the AUC ( $p=0.049$, Figure 3(a)) and the peak ( $p=0.030$, Figure $3(\mathrm{~b})$ ) of the diastolic blood pressure were elevated after inhaling $\mathrm{CO}_{2}$ compared to $\mathrm{C}$-allele carriers. No effect was found on any 
Table 1. Demographics of healthy volunteers and PD patients.

\begin{tabular}{|c|c|c|c|c|c|}
\hline & & \multicolumn{2}{|l|}{ rs10875995 } & \multicolumn{2}{|l|}{ rs685012 } \\
\hline & & $\mathrm{C} / \mathrm{C}$ and $\mathrm{C} / \mathrm{T}$ & $T / T$ & $\mathrm{C} / \mathrm{C}$ and $\mathrm{C} / \mathrm{T}$ & $\mathrm{T} / \mathrm{T}$ \\
\hline \multirow{3}{*}{$\begin{array}{l}\text { Healthy } \\
\text { volunteers }\end{array}$} & $N$ & 55 & 52 & 56 & 51 \\
\hline & Sex (\% male) & 21 & 29 & 20 & 30 \\
\hline & Age (SD) & $23.70(7.02)$ & $23.83(7.22)$ & $24.04(7.17)$ & $23.45(6.78)$ \\
\hline \multirow[t]{4}{*}{ PD patients } & $N$ & 90 & 93 & 91 & 86 \\
\hline & Sex (\% male) & 40 & 38 & 36 & 42 \\
\hline & Age (SD) & $36.06(11.55)$ & $36.22(10.37)$ & $36.18(11.63)$ & $36.31(10.36)$ \\
\hline & Duration PD (years (SD)) & $11.08(11.30)$ & $8.82(9.84)$ & $11.12(11.31)$ & $9.05(10.07)$ \\
\hline
\end{tabular}

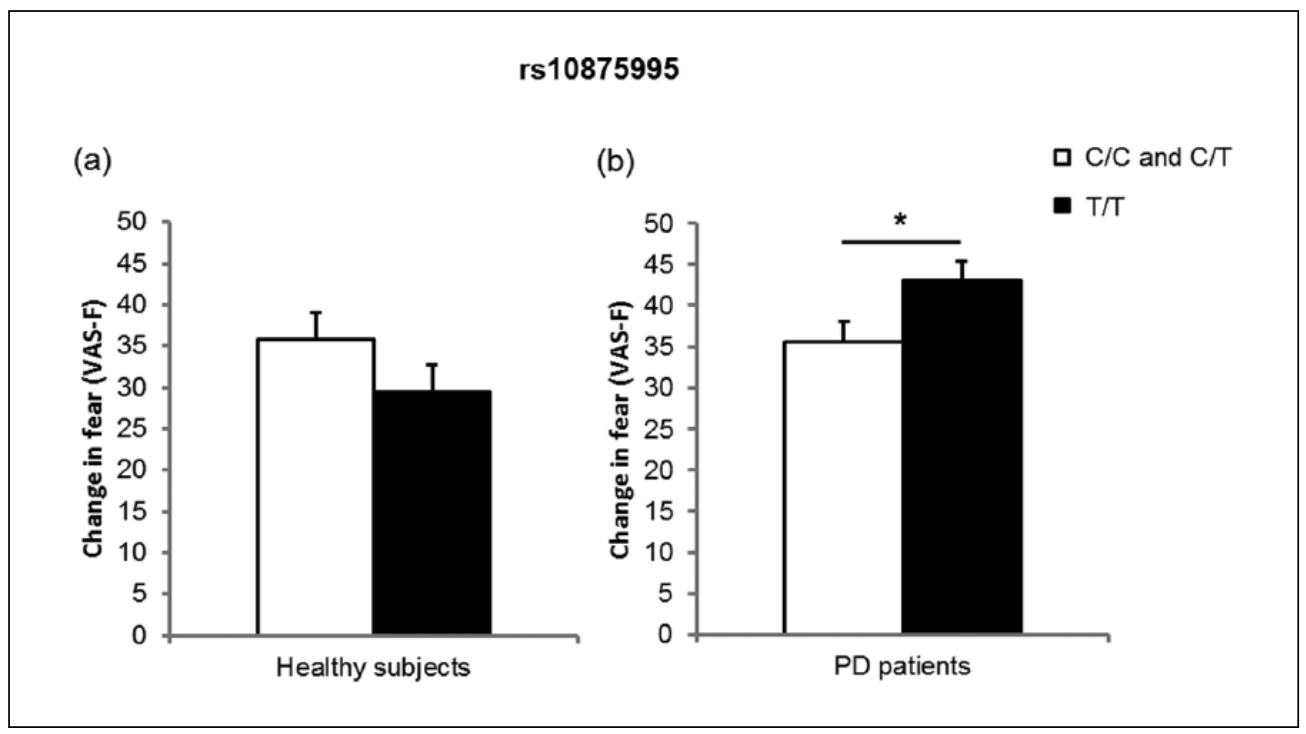

Figure 1. Effects of $\mathrm{CO}_{2}$ on the VAS-F ratings depending on the rs10875995 genotype. (a) No effect of genotype on the VAS- $\mathrm{F}$ was found in healthy subjects. (b) In PD patients, homozygous T-allele carriers scored significantly higher than C-allele carriers. ${ }^{*} p<0.05$. Data represent mean + SEM.

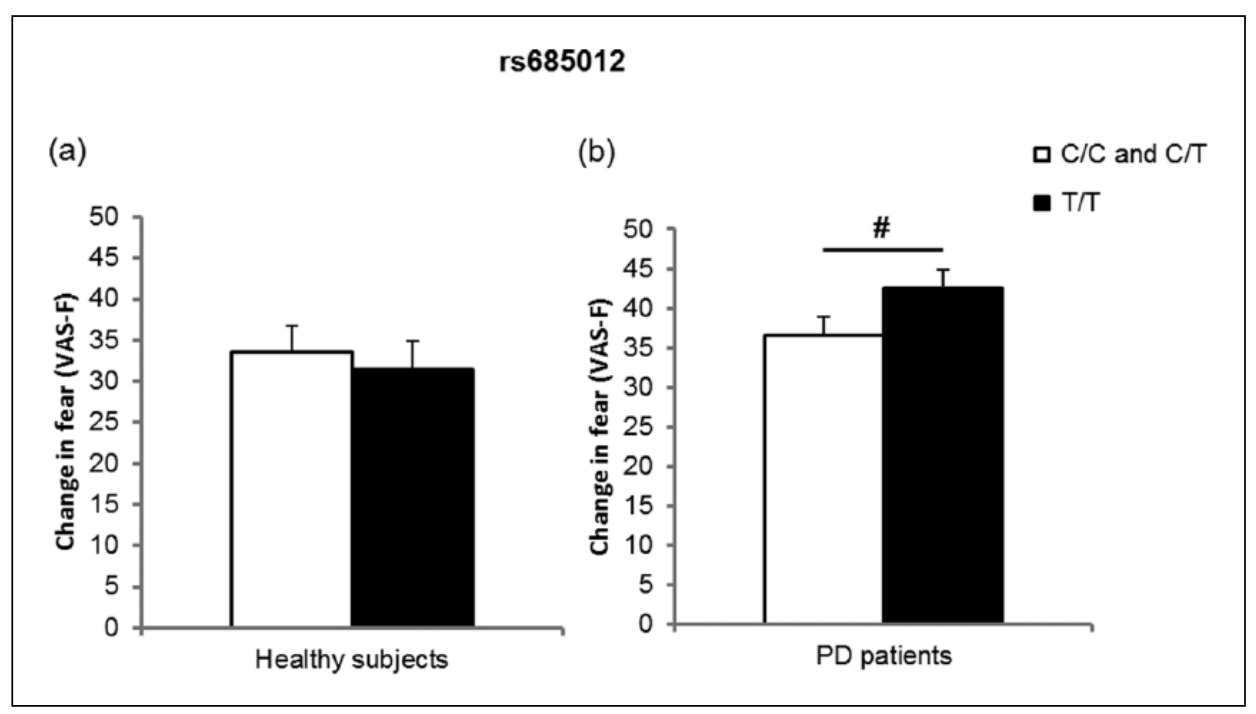

Figure 2. Effects of $\mathrm{CO}_{2}$ on the VAS-F ratings depending on the rs685012 genotype. (a) No effect of genotype was present in healthy subjects. (b) In $\mathrm{PD}$ patients, a trend towards a higher change score was found in carriers homozygous for the T-allele in comparison with $\mathrm{C}$-allele carriers. \#0.05 < $p<0.1$. Data represent mean + SEM. 


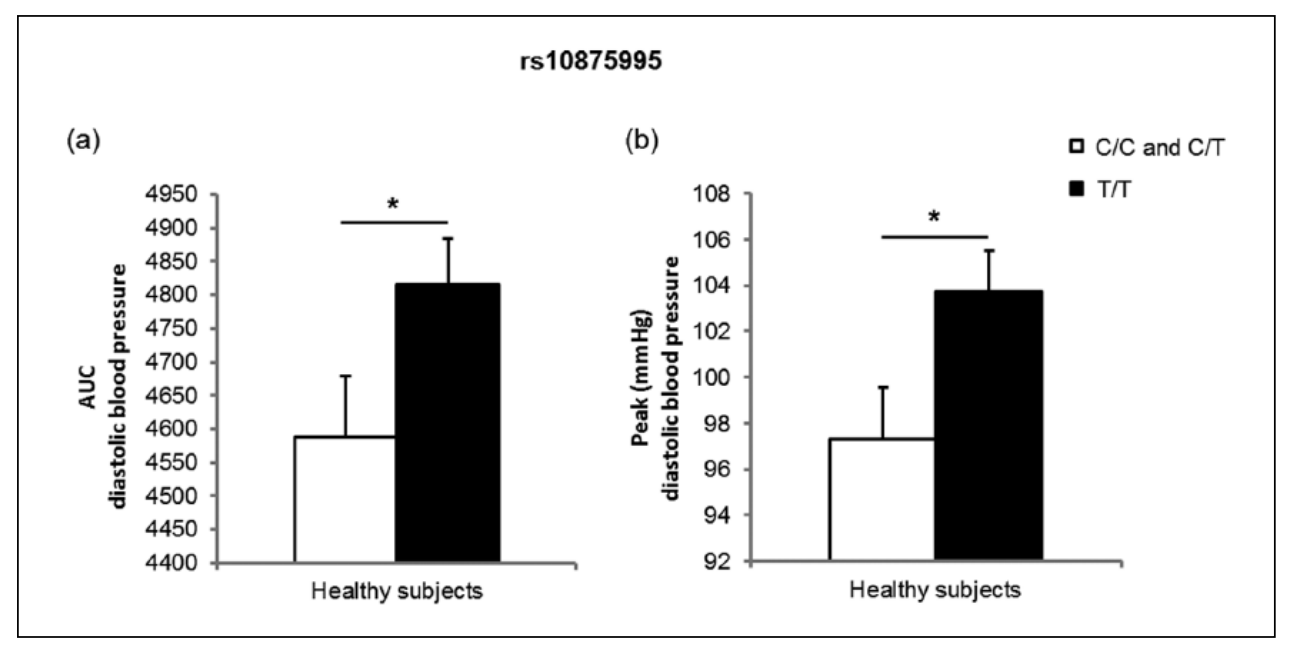

Figure 3. Effects of the rs 10875995 genotype on the diastolic blood pressure in response to $\mathrm{CO}_{2}$ in healthy subjects. (a) Homozygous T-allele carriers had a significantly higher $\mathrm{AUC}$ after inhaling $\mathrm{CO}_{2}$ compared to subjects of the $\mathrm{C} / \mathrm{C}$ and $\mathrm{C} / \mathrm{T}$ genotype. (b) The same effect was observed with regard to the peak after inhaling $\mathrm{CO}_{2} \cdot{ }^{*} p<0.05$. Data represent mean $+\mathrm{SEM}$.

outcome of heart rate (AUC $p=0.357$, peak $p=0.698$ ). With regard to rs685012, no effect was present on any outcome (Supplementary table 5).

\section{Study 2: PD patients}

Self-reports to $\mathrm{CO}_{2}$ inhalation in PD patients. In PD patients, subjects homozygous for the rs 10875995 T-allele scored significantly higher on the VAS-F in comparison with C-allele carriers ( $p=0.032$, Figure 1(b), means shown in Supplementary table 2), whilst no effect of genotype on reported PSL scores was found ( $p$ $=0.388$ ). With regard to rs685012, there was a trend towards higher VAS-F ratings in subjects with the T/T genotype in comparison with C-allele carriers $(p=0.061$, Figure 2(b)). No significant effect of $A C C N 2$ genotype on PSL scores was observed ( $p=$ 0.519 , means shown in Supplementary table 3).

Secondary analysis. Respiratory cluster analysis. We next analyzed the effect of genotype on the respiratory symptom cluster in the response to the $\mathrm{CO}_{2}$ challenge, as defined in a previous study. There was no main effect of $\operatorname{rs} 10875995$ ( $p=$ $0.659)$ or rs685012 genotype $(p=0.889)$ (means shown in Supplementary tables 2 and 3 ).

\section{Discussion}

In this study, we show an association between two genetic variants in the $A C C N 2$ gene, selected based on prior data (Smoller et al., 2014), and $\mathrm{CO}_{2}$ sensitivity in PD patients and healthy individuals. More specifically, the rs $10875995 \mathrm{~T} / \mathrm{T}$ genotype was associated with higher fear scores in patients, and with a higher blood pressure response to a $\mathrm{CO}_{2}$ panic challenge in healthy subjects compared to $\mathrm{C}$-allele carriers.

The $A C C N 2$ gene is the human orthologue of the rodent gene encoding the $\mathrm{pH}$-sensitive ion channel ASICla, which was shown to be critically involved in conditioned (Wemmie et al., 2003, 2004) as well as unconditioned $\mathrm{CO}_{2}$-induced fear behavior in mice (Ziemann et al., 2009). Therefore, ASIC1a is a prime candidate to be involved in the molecular pathophysiology of panic in humans. To date, the few previous human studies investigating an association between the $A C C N 2$ gene and $\mathrm{PD}$ reported an association of the rs685012 and/or rs10875995 C-allele with PD or anxiety disorders (Gugliandolo et al., 2016; Hettema et al., 2008; Smoller et al., 2014). Smoller and colleagues also found a larger amygdala volume and heightened functional amygdala reactivity in a sample of healthy $\mathrm{C}$-allele carriers of the rs10875995 genotype. The authors suggested that this observed amygdala-association might reflect an increased sensitivity to a decrease in $\mathrm{pH}$, secondary to neuronal activity to process the visual emotional stimulus. The elevated sensitivity would be associated with $A C C N 2$ gene variants that contribute to a decreased threshold for sensing acidosis. Furthermore, they speculated that "such activation would clearly be less direct (and less intense) than that induced by a direct $\mathrm{CO}_{2}$ inhalation."

The present studies show an rs10875995 genotype effect on the emotional as well as cardiovascular reactivity following such a direct $35 \% \mathrm{CO}_{2}$ inhalation. In PD patients, VAS-F ratings were higher in carriers homozygous for the rs 10875995 T-allele compared to C-allele carriers and consistent with this we also found a heightened cardiovascular response in healthy $\mathrm{T} / \mathrm{T}$ carriers. This is in contrast to the study by Smoller et al. (2014), in which the $\mathrm{C}$-allele was considered as risk allele. This might be explained by focusing on different phenotypes. In Smoller's study, the C-allele was shown to be associated with the diagnosis of $P D$ and with amygdala volume and function, i.e. largely anxiety-related endophenotypes, whereas the present study showed a relationship between the T-allele and experimentally provoked fear/panic sensations, i.e. specific fear-related endophenotypes. The amygdala has been implicated in rodent (Ziemann et al., 2009) and human (Holmes et al., 2012) fear behavior as well as in enhanced reactivity to emotional threats in humans (Shin and Liberzon, 2010). Furthermore, altered amygdala structure and functioning has been reported in PD patients (Kim et al., 2012). However, PD is a complex disorder and consists of different aspects (PAs, anticipatory anxiety, and avoidance behavior), which are likely 
subserved by different parts of the brain and not solely by the amygdala. While the amygdala may be most important in the conditioning process leading to avoidance behavior, the nature of PAs might be more related to other structures such as the brainstem (Goossens et al., 2014). Therefore, focusing on a complex anxiety disorder (diagnosis of PD) or a fear-specific phenotype (response to $\mathrm{CO}_{2}$ ) might lead to different results.

Moreover, observing opposite alleles associated with risk disease between studies is a known phenomenon in association studies and is referred to as "flip-flop phenomenon" (Lin et al., 2007). Although the exact cause is unknown it is assumed that it occurs when the focus is on one genetic locus while in fact many genetic variants or environmental factors, and their mutual interaction, contribute to complex phenotypes such as neuropsychiatric disorders. In addition, in spite of similar ethnicities, two populations can differ in terms of linkage disequilibrium between the two genetic loci, leading to differences in the direction of the association between studies (Lin et al., 2007). Moreover, Clarke and Cardon (2010) have calculated that the probability of finding at random flip-flop associations is negligible. Therefore, this phenomenon may have biological implications.

Given that PAs are accompanied by profound physiological symptoms, we also included cardiovascular measurements in healthy volunteers to complement self-reports. Consistent with an elevated emotional response in patients of the rs $10875995 \mathrm{~T} / \mathrm{T}$ genotype, we found a heightened cardiovascular response in healthy $\mathrm{T} / \mathrm{T}$ carriers. It has been shown that ASIC1a interacts with ASIC2, a channel implicated in baroreceptor sensitivity and thus blood pressure regulation (Lu et al., 2009). In addition, interaction of the two channels can shift the $\mathrm{pH}$ sensitivity (Wemmie et al., 2013). Currently, the functional consequences of variants in the $A C C N 2$ gene are not known. It might be speculated that the $\mathrm{T}$-variant increases the $\mathrm{pH}$ sensitivity, associated with an elevated autonomic response. In addition to cardiovascular symptoms, respiratory ones are common during PAs. PAs with prominent respiratory symptoms have been proposed as a core panic subtype (Roberson-Nay and Kendler, 2011) and Smoller et al. (2014) showed a particularly strong association between the ACCN2 genotype and the respiratory subtype in a secondary analysis. We could not confirm this in the present study, possibly due to methodological differences between the studies. We based our definition of a respiratory subtype on a cluster of six PSL sub-items in response to the $\mathrm{CO}_{2}$ inhalation, that we previously identified using a principal component factor analysis (Colasanti et al., 2008), whilst Smoller et al. (2014) grouped patients depending on the predominance of certain symptoms during real-life PAs, assessed via diagnostic interview. On the molecular level, the role of ASIC1a in respiration is still under investigation, but ASIC1a knock-out mice that do not express the protein were shown to have normal increases in minute ventilation to $\mathrm{CO}_{2}$ (Ziemann et al., 2009).

It has to be noted that we did not observe all effects consistently in both human samples. While patients having the T-allele of rs 10875995 showed an increased fear response to $\mathrm{CO}_{2}$, no effect was found in healthy volunteers. We have previously reported that a double vital capacity inhalation of $35 \% \mathrm{CO}_{2}$ in healthy volunteers induced a condition complying with the formal criteria of panic in the current psychiatric nosology (Griez et al., 2007). However, this constitutes a qualitative comparison; recently we provided a direct quantitative comparison showing that PD patients on average still show a higher sensitivity to $\mathrm{CO}_{2}$ (Leibold et al., 2016). This might explain, together with the smaller sample size in the healthy group, why the effect of genetic variation can be detected more easily in patients. Further, in patients, a moderating effect of the $A C C N 2$ genotype on VAS scores, but not on reported bodily symptoms, may be explained by the finding that the VAS is a more specific instrument than the PSL to measure reactivity to a $35 \% \mathrm{CO}_{2}$ challenge (Battaglia and Perna, 1995; Verburg et al., 1998). Similar effects were found for rs685012.

In light of the current theories about the pathophysiology of PD, we have proposed that PAs are caused by an acute metabolic disturbance of the acid-base homeostasis (Esquivel et al., 2009). Such a metabolic disturbance might form the molecular basis of Klein's suffocation false alarm theory (Klein, 1993; Preter and Klein, 2008) and can be induced by inhaling $\mathrm{CO}_{2}$. In rodents, it has been shown that ASICs are important in detecting and triggering behavioral responses to $\mathrm{CO}_{2}$ (Ziemann et al., 2009). The present study and the ones in the past few years that show an association between ASIC and PD (phenotypes) suggest that these channels might be one of the neural substrates in the alarm system in humans.

ASIC1a is expressed throughout the entire central nervous system including the brainstem (Price et al., 2014) and is a likely molecular candidate to act as chemosensor in a variety of neurons. Neurons intrinsically sensitive to $\mathrm{CO}_{2} / \mathrm{pH}$ are located within many brain structures (Biancardi et al., 2008; da Silva et al., 2011; Dean et al., 1990; Mulkey et al., 2004; Putnam et al., 2004; Ziemann et al., 2009). Some of those structures most likely serve different functions such as breathing as well as defensive behavior (Esquivel et al., 2009). The exact contribution of these brain structures in $\mathrm{CO}_{2}$ sensitivity, sensing changes in $\mathrm{pH}$ and eliciting a fear and panic-related behavioral response, is still elusive. In rodents, the amygdala has been identified as an essential brain structure in this process (Ziemann et al., 2009), while research in Urbach-Wiethe disease patients having a bilaterally dysfunctional amygdala could not confirm this (Feinstein et al., 2013). A recent functional magnetic resonance imaging study by our group (Goossens et al., 2014) suggests that, at least in humans, the brainstem is the principal brain area in sensing changes in $\mathrm{CO}_{2} / \mathrm{pH}$.

Future studies should address the relationship between variants in the $A C C N 2$ gene and the locus of brain activity in response to $\mathrm{CO}_{2}$ in a large sample. In addition, the functional consequences of those variants should be investigated. This is also interesting in relationship to cardiovascular and respiratory measures in patients, which we did not assess in the present study. Further, the exact effects of inhaling $\mathrm{CO}_{2}$ on brain $\mathrm{pH}$ in humans remain to be elucidated. In rodents, it was shown that exposure to $\mathrm{CO}_{2}$ decreases brain $\mathrm{pH}$ (Ziemann et al., 2009). In humans however, direct evidence for such a $\mathrm{CO}_{2}$-induced brain acidosis is lacking. Indirect evidence is available, provided by MRI studies showing that PD patients have a larger brain lactate response to visual stimuli (Maddock et al., 2009) and after lactate infusion (Dager et al., 1997, 1999), compared to healthy controls. Work in rodents showed that an increase in lactate causes a decrease in brain $\mathrm{pH}$ (Erlichman et al., 2008), suggesting that a similar effect may occur in humans. Combining $\mathrm{CO}_{2}$ administration and MR spectroscopy, able to non-invasively detect brain $\mathrm{pH}$ changes, may provide the lacking direct evidence. 


\section{Limitations}

The results of this study should be interpreted keeping in mind some potential limitations. First, the sample size of the present study is relatively small for genetic analyses. Due to the low number of subjects homozygous for $\mathrm{C}$, we clustered $\mathrm{C}$-allele carriers into one group to allow meaningful statistical analyses instead of a possibly more sensitive quantitative (0-1-2 alleles) approach. Second, we did not correct for multiple testing, given our confirmatory and clear hypothesis-driven approach of two highly correlated variants. Third, family history of PD was an exclusion criterion in the healthy volunteers group. With hindsight, this may have led to the inclusion of a "hyper-normal" group, thereby increasing the possibility of a type II error. This might explain the less homogeneous results in the healthy group. To increase the sensitivity on outcome measurements, future studies should include samples with a larger variation in anxiety, such as individuals with differential anxiety sensitivity or firstdegree relatives of $\mathrm{PD}$ patients.

\section{Conclusion}

The results of the present study extend on those of previous studies into the mechanisms of panic and provide the first evidence for a relationship between the $A C C N 2$ gene and the reactivity to a $\mathrm{CO}_{2}$ panic challenge in humans. Thereby, the association between the $A C C N 2$ gene and PD is strengthened and the importance of investigating both the role of variants in the $A C C N 2$ gene in humans as well as ASIC1a in rodents in the pathophysiology of panic is further supported. In the long-term, $A C C N 2$ may become a potential therapeutic target in the treatment of PD, a suggestion that is also supported by rodent research in which pharmacological inhibition of ASIC1a reduced fear-behavior (Ziemann et al., 2009).

\section{Declaration of conflicting interests}

The author(s) declared no potential conflicts of interest with respect to the research, authorship, and/or publication of this article.

\section{Funding}

The author(s) disclosed receipt of the following financial support for the research, authorship, and/or publication of this article: This work was supported by the Deutsche Forschungsgemeinschaft (DFG) Sonderforschungsbereich Transregio (SFB TRR) 58, Sonderforschungsbereich (SFB) 58/A5 to DvdH. The funding had no role in study design; in the collection, analysis and interpretation of data; in the writing of the report; and in the decision to submit the paper for publication.

\section{References}

American Psychiatric Association (2000) Diagnostic and Statistical Manual of Mental Disorders: DSM-IV-TR. 4th ed. Washington, DC: American Psychiatric Association.

American Psychiatric Association (2013) The Diagnostic and Statistical Manual of Mental Disorders. 5th ed. Arlington, VA: American Psychiatric Publishing.

Batelaan N, Smit F, de Graaf R, et al. (2007) Economic costs of full-blown and subthreshold panic disorder. $J$ Affect Disord 104: 127-136.

Battaglia $\mathrm{M}$ and Perna G (1995) The $35 \% \mathrm{CO}_{2}$ challenge in panic disorder: optimization by receiver operating characteristic (ROC) analysis. J Psychiatr Res 29: 111-119.
Biancardi V, Bicego KC, Almeida MC, et al. (2008) Locus coeruleus noradrenergic neurons and $\mathrm{CO}_{2}$ drive to breathing. Pflugers Arch 455: $1119-1128$.

Clarke GM and Cardon LR (2010) Aspects of observing and claiming allele flips in association studies. Genet Epidemiol 34: 266-274.

Cleveland WS and Devlin SJ (1988) Locally weighted regression: an approach to regression analysis by local fitting. J Am Statist Assoc 83: 596-610.

Colasanti A, Salamon E, Schruers K, et al. (2008) Carbon dioxideinduced emotion and respiratory symptoms in healthy volunteers. Neuropsychopharmacology 33: 3103-3110.

Dager SR, Friedman SD, Heide A, et al. (1999) Two-dimensional proton echo-planar spectroscopic imaging of brain metabolic changes during lactate-induced panic. Arch Gen Psychiatry 56: 70-77.

Dager SR, Richards T, Strauss W, et al. (1997) Single-voxel 1H-MRS investigation of brain metabolic changes during lactate-induced panic. Psychiatry Res 76: 89-99.

da Silva GS, Giusti H, Benedetti M, et al. (2011) Serotonergic neurons in the nucleus raphe obscurus contribute to interaction between central and peripheral ventilatory responses to hypercapnia. Pflugers Arch 462: 407-418.

Dean JB, Bayliss DA, Erickson JT, et al. (1990) Depolarization and stimulation of neurons in nucleus tractus solitarii by carbon dioxide does not require chemical synaptic input. Neuroscience 36: 207-216.

Erlichman JS, Hewitt A, Damon TL, et al. (2008) Inhibition of monocarboxylate transporter 2 in the retrotrapezoid nucleus in rats: a test of the astrocyte-neuron lactate-shuttle hypothesis. J Neurosci 28: 4888-4896.

Esquivel G, Schruers KR, Maddock RJ, et al. (2009) Acids in the brain: a factor in panic? J Psychopharmacol 24: 639-647.

Feinstein JS, Buzza C, Hurlemann R, et al. (2013) Fear and panic in humans with bilateral amygdala damage. Nat Neurosci 16: 270-272.

Goossens L, Leibold N, Peeters R, et al. (2014) Brainstem response to hypercapnia: a symptom provocation study into the pathophysiology of panic disorder. J Psychopharmacol 28: 449-456.

Griez E, de Loof C, Pols H, et al. (1990) Specific sensitivity of patients with panic attacks to carbon dioxide inhalation. Psychiatry Res 31: 193-199.

Griez EJ, Colasanti A, van Diest R, et al. (2007) Carbon dioxide inhalation induces dose-dependent and age-related negative affectivity. PLoS One 2: e987.

Griez EJ, Lousberg H, van den Hout MA, et al. (1987) $\mathrm{CO}_{2}$ vulnerability in panic disorder. Psychiatry Res 20: 87-95.

Gugliandolo A, Gangemi C, Caccamo D, et al. (2016) The RS685012 polymorphism of ACCN2, the human ortholog of murine acidsensing ion channel (ASIC1) gene, is highly represented in patients with panic disorder. Neuromolecular Med 18: 91-98.

Hettema JM, An SS, Neale MC, et al. (2008) Lack of association between the amiloride-sensitive cation channel 2 (ACCN2) gene and anxiety spectrum disorders. Psychiatr Genet 18: 73-79.

Holmes AJ, Lee PH, Hollinshead MO, et al. (2012) Individual differences in amygdala-medial prefrontal anatomy link negative affect, impaired social functioning, and polygenic depression risk. J Neurosci 32: 18087-18100.

Kim JE, Dager SR and Lyoo IK (2012) The role of the amygdala in the pathophysiology of panic disorder: evidence from neuroimaging studies. Biol Mood Anxiety Disord 2: 20.

Klaassen T, Klumperbeek J, Deutz NE, et al. (1998) Effects of tryptophan depletion on anxiety and on panic provoked by carbon dioxide challenge. Psychiatry Res 77: 167-174.

Klein DF (1993) False suffocation alarms, spontaneous panics, and related conditions. An integrative hypothesis. Arch Gen Psychiatry 50: 306-317.

Leibold NK, van den Hove DL, Viechtbauer W, et al. (2016) $\mathrm{CO}_{2}$ exposure as translational cross-species experimental model for panic. Transl Psychiatry 6: e885. 
Leibold NK, Viechtbauer W, Goossens L, et al. (2013) Carbon dioxide inhalation as a human experimental model of panic: the relationship between emotions and cardiovascular physiology. Biol Psychol 94: 331-340.

Lin PI, Vance JM, Pericak-Vance MA, et al. (2007) No gene is an island: the flip-flop phenomenon. Am J Hum Genet 80: 531-538.

Lu Y, Ma X, Sabharwal R, et al. (2009) The ion channel ASIC2 is required for baroreceptor and autonomic control of the circulation. Neuron 64: 885-897.

Maddock RJ, Buonocore MH, Copeland LE, et al. (2009) Elevated brain lactate responses to neural activation in panic disorder: a dynamic 1H-MRS study. Mol Psychiatry 14: 537-545.

Mulkey DK, Stornetta RL, Weston MC, et al. (2004) Respiratory control by ventral surface chemoreceptor neurons in rats. Nat Neurosci 7: 1360-1369.

Nakashima K, Yamashita T, Kashiwagi S, et al. (1996) The effect of sodium bicarbonate on $\mathrm{CBF}$ and intracellular $\mathrm{pH}$ in man: stable Xe-CT and 31P-MRS. Acta Neurol Scand Suppl 166: 96-98.

Nardi AE, Valenca AM, Lopes FL, et al. (2006) Psychopathological profile of $35 \% \mathrm{CO}_{2}$ challenge test-induced panic attacks: a comparison with spontaneous panic attacks. Compr Psychiatry 47: 209-214.

Preter M and Klein DF (2008) Panic, suffocation false alarms, separation anxiety and endogenous opioids. Prog Neuropsychopharmacol Biol Psychiatry 32: 603-612.

Price MP, Gong H, Parsons MG, et al. (2014) Localization and behaviors in null mice suggest that ASIC1 and ASIC2 modulate responses to aversive stimuli. Genes Brain Behav 13: 179-194.

Putnam RW, Filosa JA and Ritucci NA (2004) Cellular mechanisms involved in $\mathrm{CO}(2)$ and acid signaling in chemosensitive neurons. $\mathrm{Am}$ J Physiol Cell Physiol 287: C1493-1526.

Rhoades RA and Bell DR (2009) Medical Physiology: Principles for Clinical Medicine. Philadelphia, PA: Lippincott Williams \& Wilkins.

Roberson-Nay R and Kendler KS (2011) Panic disorder and its subtypes: a comprehensive analysis of panic symptom heterogeneity using epidemiological and treatment seeking samples. Psychol Med 41: 2411-2421.

Schruers K, Esquivel G, van Duinen M, et al. (2011) Genetic moderation of $\mathrm{CO}_{2}$-induced fear by 5-HTTLPR genotype. $J$ Psychopharmacol 25: $37-42$.
Schruers KRJ, Van De Mortel H, Overbeek T, et al. (2004) Symptom profiles of natural and laboratory panic attacks. Acta Neuropsychiatr 16: 101-106.

Schuchmann S, Schmitz D, Rivera C, et al. (2006) Experimental febrile seizures are precipitated by a hyperthermia-induced respiratory alkalosis. Nat Med 12: 817-823.

Sheehan DV, Lecrubier Y, Sheehan KH, et al. (1998) The MiniInternational Neuropsychiatric Interview (MINI): the development and validation of a structured diagnostic psychiatric interview for DSM-IV and ICD-10. J Clin Psychiatry 59(Suppl 20): 22-33;quiz 34-57.

Shin LM and Liberzon I (2010) The neurocircuitry of fear, stress, and anxiety disorders. Neuropsychopharmacology 35: 169-191.

Smoller JW (2011) Who's afraid of anxiety genetics? Biol Psychiatry 69: 506-507.

Smoller JW, Gallagher PJ, Duncan LE, et al. (2014) The human ortholog of acid-sensing ion channel gene ASIC1a is associated with panic disorder and amygdala structure and function. Biol Psychiatry 76: 902-910.

Verburg K, Pols H, de Leeuw M, et al. (1998) Reliability of the 35\% carbon dioxide panic provocation challenge. Psychiatry Res 78: 207-214.

Wemmie JA, Askwith CC, Lamani E, et al. (2003) Acid-sensing ion channel 1 is localized in brain regions with high synaptic density and contributes to fear conditioning. J Neurosci 23: 5496-5502.

Wemmie JA, Coryell MW, Askwith CC, et al. (2004) Overexpression of acid-sensing ion channel 1a in transgenic mice increases acquired fear-related behavior. Proc Natl Acad Sci U S A 101: 3621-3626.

Wemmie JA, Taugher RJ and Kreple CJ (2013) Acid-sensing ion channels in pain and disease. Nat Rev Neurosci 14: 461-471.

Yonkers KA, Bruce SE, Dyck IR, et al. (2003) Chronicity, relapse, and illness-course of panic disorder, social phobia, and generalized anxiety disorder: findings in men and women from 8 years of follow-up. Depress Anxiety 17: 173-179.

Ziemann AE, Allen JE, Dahdaleh NS, et al. (2009) The amygdala is a chemosensor that detects carbon dioxide and acidosis to elicit fear behavior. Cell 139: 1012-1021.

Ziemann AE, Schnizler MK, Albert GW, et al. (2008) Seizure termination by acidosis depends on ASIC1a. Nat Neurosci 11: 816-822. 